Валиахметова Г. Н. Отношения между Республикой Корея и ОАЭ в последней четверти XX - XXI веках : от экономического взаимодействия к особому стратегическому партнерству / Г. Н. Валиахметова, И. А. Мусинова // Научный диалог. - 2021. - № 5. - С. $327-$ 337. - DOI: 10.24224/2227-1295-2021-5-327-337.

Valiakhmetova, G. N., Musinova, I. A. (2021). Relations between Republic of Korea and United Arab Emirates in Last Quarter of XX-XXI Centuries: from Economic Interaction to Special Strategic Partnership. Nauchnyi dialog, 5: 327-337. DOI: 10.24224/2227-1295-2021-5-327-337. (In Russ.).

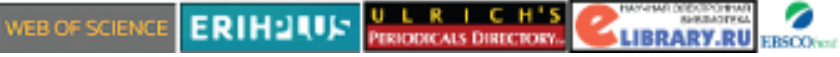

Журнал включен в Перечень ВАК

Отношения между

Республикой Корея и ОАЭ

в последней четверти

XX - XXI веках:

от экономического

взаимодействия к особому

стратегическому

партнерству

Валиахметова Гульнара Ниловна orcid.org/0000-0001-7199-7723

доктор исторических наук, заведующий кафедрой востоковедения

Уральский гуманитарный институт vgulnara@mail.ru

Мусинова Ирина Александровна orcid.org/0000-0003-3678-6335

старший преподаватель кафедры востоковедения

Уральский гуманитарный институт irina.musinova@gmail.com

Уральский федеральный университет имени первого Президента России Б. Н. Ельцина

(Екатеринбург, Россия)

\section{Relations between Republic of Korea and United Arab Emirates in Last Quarter of XX-XXI Centuries: from Economic Interaction to Special Strategic Partnership}

Gulnara N. Valiakhmetova orcid.org/0000-0001-7199-7723 Doctor of History

Head of the Department of Oriental Studies Ural Humanitarian Institute vgulnara@mail.ru

Irina A. Musinova orcid.org/0000-0003-3678-6335

Senior Lecturer

Department of Oriental Studies Ural Humanitarian Institute irina.musinova@gmail.com

Ural Federal University named after First President of Russia Boris N. Yeltsin

(Yekaterinburg, Russia)

(С) Валиахметова Г. Н., Мусинова И. А., 2021 


\section{ОРИГИНАЛЬНЫЕ СТАТЬИ}

\section{Аннотация:}

Рассматривается эволюция двусторонних отношений Республики Корея и Объединенных Арабских Эмиратов (ОАЭ) в контексте формирования ближневосточного направления внешней политики Сеула в 1980-2010-х годах. Выявлен и проанализирован комплекс факторов, способствовавших выстраиванию конструктивного диалога Южной Кореи с арабскими монархиями Персидского залива и арабским миром в целом. Предлагается периодизация истории развития корейско-эмиратских отношений, представлена характеристика ее основных этапов, а также нормативно-правовых и институциональных основ двустороннего сотрудничества. Особое внимание уделяется анализу трансформации концептуальных подходов, методов и дипломатических инструментов продвижения национальных интересов Республики Корея в ОАЭ. Раскрываются причины отхода Сеула от ориентации исключительно на экономическое взаимодействие с ОАЭ и включения Южной Кореи в политическую повестку Ближнего Востока, а также решение актуальных проблем обеспечения региональной безопасности. Подчеркивается роль южнокорейских президентов в усилении геополитических позиций страны на Ближнем Востоке. Утверждается, что установление стратегического партнерства с ОАЭ позволило Республике Корея совершить прорыв на ближневосточном направлении и создать благоприятные условия для интеграции ОАЭ в мировые политические и экономические процессы в качестве равноправного партнера.

\section{Ключевые слова:}

Республика Корея; ОАЭ; Ближний Восток; двусторонние отношения; стратегическое партнерство.

\section{ORIGINAL ARTICLES}

\section{Abstract:}

The evolution of bilateral relations between the Republic of Korea and the United Arab Emirates (UAE) in the context of the formation of the Middle East direction of Seoul's foreign policy in the 1980s and 2010s is considered. The author identifies and analyzes a set of factors that contributed to building of a constructive dialogue between South Korea and the Arab monarchies of the Persian Gulf and the Arab world as a whole. A periodization of the history of the development of the Korean-Emirati relations is proposed, a description of its main stages, as well as the legal and institutional foundations of bilateral cooperation is presented. Particular attention is paid to the analysis of the transformation of conceptual approaches, methods and diplomatic tools for promoting the national interests of the Republic of Korea in the UAE. The author reveals the reasons for Seoul's withdrawal from focusing solely on economic interaction with the UAE and the inclusion of South Korea in the political agenda of the Middle East, as well as the solution of urgent problems of ensuring regional security. The role of the South Korean presidents in strengthening the country's geopolitical positions in the Middle East is emphasized. It is argued that the establishment of a strategic partnership with the UAE allowed the Republic of Korea to make a breakthrough in the Middle East and create favorable conditions for the integration of the UAE into world political and economic processes as an equal partner.

\section{Key words:}

Republic of Korea; UAE; Near East; bilateral relations; strategic partnership. 


\section{Отношения между Республикой Корея и ОАЭ в последней четверти XX - XXI веках: от экономического взаимодействия к особому стратегическому партнерству}

Валиахметова Г. Н, Мусинова И. А., 2021

\section{1. Введение}

В XXI веке Ближний Восток остается самым нестабильным регионом мира, сохраняя при этом статус главной «нефтяной кладовой» планеты и, соответственно, свою исключительную значимость в мировой экономике. Это повышает роль мирового сообщества в снижении конфликтного потенциала региона, в том числе путем интеграции ближневосточных стран в международные экономические и политические процессы. Последние десятилетия в реализацию указанных задач все более вовлекаются новые внерегиональные игроки в лице КНР, Японии и Республики Корея (далее также - РК). Их продвижение на Ближний Восток демонстрирует ряд существенных отличий от практики традиционных для региона внешних акторов (США, России, стран Европы) и требует научного осмысления. Особый академический и политический интерес представляет исторический опыт Южной Кореи. За относительно короткий исторический период политика Сеула в регионе трансформировалась из пассивной и ориентированной исключительно на собственные экономические интересы в эффективную стратегию, которая вывела Республику Корея в число ведущих внерегиональных и глобальных держав.

Сегодня Южная Корея имеет широкий спектр интересов на Ближнем Востоке. Их реализация осуществляется в рамках двустороннего и многостороннего взаимодействия со странами региона с использованием методов экономической, публичной, цифровой, культурной и религиозной дипломатии, а также путем политического и военного участия в миротворческой деятельности. При этом Сеул демонстрирует согласованность своих действий в регионе с Вашингтоном. Единственным исключением из данного правила стали отношения Южной Кореи с Объединенными Арабскими Эмиратами, которые Сеул вывел на уровень особого стратегического партнерства, причем без оглядки на США. Этот новый формат сотрудничества не только способствовал активизации отношений РК с ОАЭ и арабскими странами Персидского залива, но также придал мощный импульс развитию трансрегиональных связей между Ближним Востоком и Восточной Азией [Song, 2013, p. 41-42]. 
Почему именно ОАЭ вышли на приоритетные позиции в ближневосточной стратегии РК? Почему именно в отношениях с Абу-Даби впервые проявилась независимость ближневосточной дипломатии Сеула? Исследователи Южной Кореи и стран Ближнего Востока объясняют это комплексом причин исторического, международно-политического, экономического, внутриполитического, культурного и религиозного характера. При всей обширности и разнообразии исследовательской тематики, посвященной роли ОАЭ в политике Южной Кореи на Ближнем Востоке, дискуссии по вышеупомянутым вопросам пока далеки от завершения.

Специфика продвижения на Ближнем Востоке национальных интересов новых внерегиональных акторов представляет собой относительно не изученное направление исследований в России, причем российские ученые преимущественное внимание уделяют китайскому кейсу. Данная работа, нацеленная на выявление исторических этапов и особенностей трансформации стратегий и методов реализации ближневосточной политики Южной Кореи на примере развития ее отношений с ОАЭ в период с 1980 года до настоящего времени, позволяет в определенной степени восполнить указанный пробел.

\section{2. Предпосылки сближения РК и ОАЭ в конце XX — начале XXI веков}

Ближний Восток относительно долго оставался на периферии внешнеполитических интересов Республики Корея, поскольку ключевая роль в обеспечении национальной безопасности страны отводилась развитию отношений с США и государствами Восточной Азии. Успешная модернизация в период президентства Пак Чонхи (1963-1979) и нефтяной бум 1973 года способствовали возрастанию значимости Ближнего Востока для динамично развивающейся экономики Южной Кореи, а разрядка международной напряженности позволила Сеулу преодолеть ограничительные рамки холодной войны и к началу 1980-х годов установить дипломатические отношения практически со всеми странами региона. Это заложило основы формирования ближневосточного направления во внешней политике РК, важной составляющей которого стало взаимодействие с ОАЭ.

Первым этапом в истории двусторонних отношений РК и ОАЭ можно считать период от установления дипломатических отношений в 1980 году до начала 2003 года. Он характеризуется постепенной активизацией межгосударственного взаимодействия по вопросам нефтяных поставок, трудовой миграции и продвижения деловых интересов Южной Кореи в ОАЭ (строительный бизнес, экспорт бытовой техники и т. д.). В это время Сеул еще не рассматривал Ближний Восток в долгосрочной перспективе, по- 
этому региональная политика как таковая практически отсутствовала, а решения принимались по каждому отдельному случаю в бюрократических кабинетах Министерства иностранных дел [Azad, 2013, p. 553].

В данный период интересы Южной Кореи на Ближнем Востоке ограничивались исключительно торгово-экономической сферой, а залогом их успешного продвижения в немалой степени стало очевидное стремление Сеула дистанцироваться от участия в политической повестке региона. Вместе с тем окончание холодной войны, глобализация, усиление зависимости южнокорейской экономики от нефтяного импорта и рост турбулентности на Ближнем Востоке в условиях постбиполярного мира поставили перед РК вопрос о необходимости разработки комплексных мер защиты национальных энергетических интересов путем диверсификации двусторонней торговли со странами региона, а также политического и военного участия в урегулировании региональных конфликтов [Levkowitz, 2013, p. 10-12].

\section{3. Основные направления диверсификации двусторонних связей: от ресурсной дипломатии к сотрудничеству в области безопасности}

Приход к власти президента Но Мухёна (2003-2008) ознаменовал начало качественно нового этапа в развитии отношений РК и ОАЭ. О начале кардинальных перемен в ближневосточной политике Сеула свидетельствовали акценты на сферу безопасности и продвижение многосторонних форматов взаимодействия, прежде всего с Советом сотрудничества арабских государств Персидского залива (далее - ССАГПЗ). 15 ноября 2006 года РК и ССАГПЗ подписали первый меморандум о взаимопонимании в военной сфере и начали переговоры о создании зон свободной торговли. Это символизировало отход Сеула от традиционной ориентации во внешней политике на взаимодействие с США и странами Восточной Азии [Jeong, 2019, p. 226-228].

Но Мухён стал первым южнокорейским президентом, посетившим ОАЭ. За его визитом в Абу-Даби 12 мая 2006 года последовало подписание Соглашения о сотрудничестве в сфере безопасности (2007), ставшего исключительно важной вехой в истории двусторонних отношений. Деятельность учрежденного тогда же Совместного экономического совета РК и ОАЭ способствовала взрывному росту двусторонней торговли, увеличению корейских инвестиций в инфраструктурные проекты ОАЭ и строительному буму, символом которого стала знаменитая башня Бурж-Халифа в Дубае, построенная корпорацией «Самсунг». В рассматриваемый период, кроме того, были заложены основы ресурсной дипломатии РК, которая была нацелена на получение прямого доступа к нефтегазовым месторождениям Ближнего Востока и дала свои результаты в ОАЭ при преемниках Но Мухёна [Al-Sudairi, 2012, p. 4-7; Jeong, 2019, p. 231]. В дополнение 
к методам вертикальной дипломатии стали создаваться новые форматы многостороннего взаимодействия (Форум сотрудничества Кореи и Ближнего Востока и др.) [Korea Middle East ..., 2020].

Третий период связан с президентством Ли Мёнбака (2008-2013) и может быть охарактеризован как триумф южнокорейской дипломатии на Ближнем Востоке, основой которого стало соглашение о стратегическом партнерстве между РК и ОАЭ. Ли Мёнбак был первым и единственным президентом Южной Кореи, который хорошо знал специфику и деловую культуру региона: за 27 лет своей карьеры в корпорации «Хёндай» он руководил множеством ближневосточных проектов. Это в немалой степени позволило ему расширить и углубить устоявшиеся интересы Сеула в регионе [Azad, 2013, p. 553-555].

Смещение фокуса ближневосточной политики РК на арабские монархии Персидского залива в данный период было обусловлено наличием здесь внушительных запасов нефти и газа, географическими преимуществами, относительной схожестью и стабильностью их политических систем, а также запуском стратегических программ диверсификации экономики, позволяющих им интегрироваться в глобальные процессы современности [Al-Sudairi, 2012, p. 3-4; Azad, 2013, p. 555-557; Jeong, 2019, p. 227$].$

Одной из ключевых особенностей в отношениях РК и ОАЭ эпохи Ли Мёнбака стало тесное взаимодействие с правящей семьей ОАЭ и беспрецедентное количество официальных визитов на высоком уровне (39 взаимных посещений на уровне глав государств и министров), что запустило аналогичные процессы в деловых кругах обеих стран и способствовало созданию атмосферы доверия [Azad, 2013, p. 553-555; Jeong, 2019, p. 231-232]. Развитие инструментов вертикальной и горизонтальной дипломатии позволило Сеулу совершить прорыв на ближневосточном направлении.

В 2009 году южнокорейские корпорации при прямом участии Ли Мёнбака выиграли контракт на развитие ядерной энергетики в ОАЭ на 40 млрд долларов. Этот самый крупный в истории РК зарубежный контракт стал для Сеула пропуском на глобальный рынок ядерно-энергетических технологий, который традиционно контролировали США, Франция, Япония, Россия и Китай. Об открытии перед Южной Кореей колоссальных перспектив свидетельствовали начавшиеся вскоре переговоры с Иорданией, Турцией, Саудовской Аравией и Катаром о строительстве атомных электростанций [Levkowitz, 2013, p. 20]. Но главным преимуществом и новаторством ядерного соглашения РК и ОАЭ стал совместный характер будущих предприятий по эксплуатации и техническому обслуживанию реакторов в течение не менее 60 лет. Договор символизировал переход двусторонних отношений на уровень стратегического партнерства [Azad, 
2013, p. 560 - 561]. Для дальнейшей консолидации усилий с РК в экономической сфере в мае 2010 года Абу-Даби учредил Деловой совет ОАЭ по Kopee [UAE-Korea ..., 2011].

На основе стратегического партнерства с ОАЭ Южная Корея добилась значительного прогресса в обеспечении своей национальной энергетической безопасности, которая и сегодня остается главным приоритетом ее ближневосточной политики. В 2009-2011 годах Сеул и Абу-Даби договорились о совместной разведке и разработке нефтяных месторождений ОАЭ, о строительстве резервных нефтехранилищ для РК в ОАЭ и в корейских морских портах. Эти соглашения вывели Южную Корею, находящуюся в жесткой зависимости от нефтегазового импорта, в число крупных продуцентов нефти и гарантировали стабильность снабжения корейской экономики энергоносителями в среднесрочной перспективе [Al-Sudairi, 2012, p. 4-6; Levkowitz, 2013, p. 18; Song, 2013, p. 28-31].

Стратегическое партнерство РК и ОАЭ распространилось также в области строительства, возобновляемой энергетики, инвестиций, высоких технологий, медицины и фармакологии, сельского хозяйства и туризма. Новыми сферами двустороннего сотрудничества стал широкий спектр научных, образовательных, культурных, спортивных мероприятий и обменных программ [Al-Sudairi, 2012, p. 8-15; Jeong, 2019, p. 240-244]. Для развития многосторонних связей с ОАЭ и арабскими странами в области политики, бизнеса, экономики и культуры в 2008 году в Сеуле было учреждено Корейско-арабское общество [Korean-Arab Society ..., 2020]. Hемаловажную роль в продвижении конструктивного диалога между Сеулом и Абу-Даби сыграли исламские общественные организации и группы Южной Кореи, деятельность которых позволила значительно улучшить имидж страны в арабо-мусульманском мире [Song, 2015, p. 68-72].

$\mathrm{C}$ политической точки зрения наиболее значимым стало расширение стратегического партнерства РК и ОАЭ на военную сферу. В 2011 году Сеул направил 130 военнослужащих для обеспечения военной подготовки и снаряжения спецназа ОАЭ. Это был первый случай прямого военного присутствия Южной Кореи в районах, где не велись боевые действия. Сеул объяснял данный прецедент необходимостью обеспечения гарантий защиты корейских граждан и инвестиций на Ближнем Востоке. Двусторонние отношения в сфере безопасности получили дополнительный стимул к развитию также после инцидента с захватом южнокорейского грузового судна сомалийскими пиратами в 2011 году, когда правящий дом ОАЭ оказал содействие Сеулу в решении проблемы [Song, 2013, p. 31-38].

Четвертый, текущий, период в развитии отношений между Сеулом и Абу-Даби связан с деятельностью преемников Ли Мёнбака на посту пре- 
зидента Южной Кореи - Пак Кынхе (2013 - 2017) и Мун Джэина (2017 — до настоящего времени). Это время характеризуется движением к выстраиванию всеобъемлющего стратегического партнерства, в рамках которого приоритет экономического сотрудничества все больше уступает место политическим императивам и интересам безопасности. Соответственно, ресурсная дипломатия утрачивает свою ведущую роль, на передний план выходят методы вертикальной дипломатии и многосторонние форматы взаимодействия с ОАЭ в рамках ССАГПЗ, Лиги арабских государств, Организации исламского сотрудничества. Расширение сотрудничества в сфере обороны и вооружений базируется на обоюдном стремлении Сеула и Абу-Даби к сдерживанию Ирана и восстановлению баланса региональной безопасности [Azad, 2018, p. 263-265; Chun, 2016, p. 31-32]. Значительно повышается роль межкультурного диалога и инструментов «мягкой» силы [Jeong, 2019, p. 244; Park et al., 2017, p. 33-39], создаются новые общественные институты (Эмиратско-корейское общество дружбы, Корейский культурный центр в ОАЭ и др.), расширяется посредническая деятельность мусульманских организаций Южной Кореи [Song, 2015, p. 69-70].

Визиты Мун Джэина в Абу-Даби в марте 2018 года и наследного принца Абу-Даби Мухаммада ибн Зайд ал-Нахайяна в Сеул в феврале 2019 года повышают статус отношений РК и ОАЭ до особого стратегического партнерства. На этой основе подписан целый ряд меморандумов о взаимопонимании в области науки и информационно-коммуникационных технологий, здравоохранения, малого и среднего бизнеса, возобновляемых источников энергии, инфраструктурных проектов, управления интеллектуальной собственностью [Jeong, 2019, p. 233; Lee, 2016, p. 10-12; Renewable Energy ..., 2019 , p. 46-78]. Весьма символичным стало то, что к 40-летию установления дипломатический отношений Сеул и Абу-Даби учредили новый формат взаимодействия - культурный диалог ОАЭ и Кореи 2020 [The United Arab Emirates ..., 2019]. Он нацелен на сближение культур и обмен знаниями, продвижение инициатив и идей в областях, связанных с сохранением и развитием духовного и материального наследия двух наций.

\section{4. Заключение}

Пример ОАЭ демонстрирует ключевые тренды развития отношений Республики Корея со странами Ближнего Востока. Включение региона в сферу жизненных интересов Южной Кореи было обусловлено разрушением традиционных структур международной безопасности после распада биполярной системы, ростом нефтяных потребностей страны и расширением возможностей для корейского бизнеса в этой части света ввиду начавшихся процессов глобализации. До начала XXI века ближневосточная 
политика РК находилась под сильным влиянием США. Однако по мере осознания специфики геополитического и религиозно-культурного пространства региона Сеул выработал собственный подход к взаимодействию с его ведущими государствами, в число которых в первую очередь были включены наиболее развитые экономически и политически стабильные нефтедобывающие монархии Персидского залива, взявшие курс на диверсификацию национальных экономик.

Установление стратегического партнерства с ОАЭ позволило Южной Корее совершить прорыв на ближневосточном направлении, выйти за узкие рамки экономических интересов и трансформироваться в ответственную державу, способную внести существенный вклад в создание новой системы региональной безопасности и интеграцию стран Ближнего Востока в глобальную экономику в качестве равноправных участников. ОАЭ стала для РК четвертой страной (после США, Австралии и Индии), отношения с которой имеют особый стратегический статус.

Успех Республики Корея в продвижении своих национальных интересов в ОАЭ в немалой степени базируется на прагматизме корейской политической и деловой элиты, понимании и умении принять в расчет весь комплекс многочисленных и противоречивых факторов, влияющих на процесс принятия решений в Абу-Даби. Анализ истории взаимодействия Южной Кореи и ОАЭ позволяет сделать вывод о взаимовыгодном характере двусторонних отношений и их движении к модели инновационно-ориентированного партнерства.

\section{Источники}

1. Korean-Arab Society : Main Activities, 2020 [Electronic resource]. - Access mode : http://eng.korea-arab.org/ (accessed 6.03.2021).

2. Korea Middle East Cooperation Forum, 2020 [Electronic resource]. — Access mode : http://eng.korea-arab.org/?c=user\&mcd=forum (accessed 10.03.2021).

3. Renewable Energy Market Analysis : GCC 2019. — Abu Dhabi : International Renewable Energy Agency (IRENA), 2019. — 154 p. — ISBN 978-92-9260-096-9.

4. The United Arab Emirates and the Republic of Korea launch the UAE-Korea Cultural Dialogue 2020 in Seoul, 2019 [Electronic resource]. - Access mode : https://www.mckd. gov.ae/en/news/the-united-arab-emirates-and-the-republic-of-korea-launch-the-uae-koreacultural-dialogue-2020-in-seoul/ (accessed 10.03.2021).

5. UAE-Korea Business Council Established to Strengthen Commercial Ties, 2011 [Electronic resource]. — Access mode : https:/www.enec.gov.ae/news/latest-news/uae-koreabusiness-council-established-to-strengthen-commercial-ties/ (accessed 17.03.2021).

\section{ЛИТЕРАТУРА}

1. Al-Sudairi M. T. South Korea-GCC Economic Relations : An Overview / M. T. AlSudairi. - Abu Dhabi : Gulf Research Center, 2012. — 16 p. 
2. Azad S. Déjà vu diplomacy : South Korea's Middle East policy under Lee Myungbak / S. Azad // Contemporary Arab Affairs. — 2013. — № 6 (4). — Pp. 552 — 566. — DOI: 10.1080/17550912.2013.850772.

3. Azad S. In Quest of a Second Boom. South Korea's Middle East Policy under Park Geun-hye / S. Azad // Contemporary Arab Affairs. — 2018. — № 11 (1-2). — Pp. $257-$ 278. - DOI: 10.1525/caa.2018.000015.

4. Chun C. East Asian Security and South Korea's Middle Power Diplomacy / C. Chun // Transforming Global Governance with Middle Power Diplomacy : South Korea's Role in the 21st Century / Ed. by S. J. Lee. — New York : Palgrave Macmillan, 2016. — Pp. 15-34. ISBN 978-1-137-59359-7.

5. Jeong H. W. Beyond Resource Diplomacy and Economic Statecraft : UAE-ROK Relations in the 21st Century / H. W. Jeong // Asian Journal of Middle Eastern and Islamic Studies. — 2019. — № 13 (2). — Pp. 226-245. — DOI : 10.1080/25765949.2019.1605569.

6. Lee S. J. South Korea Aiming to Be an Innovative Middle Power / S. J. Lee // Transforming Global Governance with Middle Power Diplomacy : South Korea's Role in the 21st Century / Ed. by S. J. Lee. — New York : Palgrave Macmillan, 2016. — Pp. 1-13. ISBN 978-1-137-59359-7.

7. Levkowitz A. South Korea's Middle East Polic / A. Levkowitz. - A. Ramat Gan : The Begin-Sadat Center for Strategic Studies, 2013. - 38 p. - ISSN 0793-1042.

8. Park Y. E. Predicting Arab Consumers' Preferences on the Korean Contents Distribution / Y. E. Park, S. Chaffar, M.-S. Kim, H. Y. Ko // Journal of Distribution Science. 2017. — № 15 (4). — Pp. 33 - 40. — DOI: 10.15722/jds.15.4.201704.33.

9. Song N. Islam and South Korea's Middle East Diplomacy / N. Song // BAKS Papers. 2015. — № 16 (3). — Pp. 60-75.

10. Song N. The Strategic Partnership between South Korea and the United Arab Emirates / N. Song // Güvenlik Stratejileri Dergisi (Security Strategies Journal). — 2013. № 17 (9). - Pp. $23-48$.

\section{Material ResourCes}

Korean-Arab Society: Main Activities (2020). Available at: http://eng.korea-arab.org/ (accessed 06.03.2021).

Korea Middle East Cooperation Forum (2020). Available at: http://eng.korea-arab. org/?c=user\&mcd=forum (accessed 10.03.2021).

Renewable Energy Market Analysis: GCC 2019. (2919). Abu Dhabi: International Renewable Energy Agency (IRENA). 154 p. ISBN 978-92-9260-096-9.

The United Arab Emirates and the Republic of Korea launch the UAE-Korea Cultural Dialogue 2020 in Seoul (2019). Available at: https://www.mckd.gov.ae/en/news/theunited-arab-emirates-and-the-republic-of-korea-launch-the-uae-korea-culturaldialogue-2020-in-seoul/ (accessed 10.03.2021).

UAE-Korea Business Council Established to Strengthen Commercial Ties (2011). Available at: https://www.enec.gov.ae/news/latest-news/uae-korea-business-council-established-to-strengthen-commercial-ties/ (accessed 17.03.2021).

\section{REFERENCES}

Al-Sudairi, M. T. (2012). South Korea-GCC Economic Relations: An Overview. Abu Dhabi: Gulf Research Center. 16 p. 
Azad, S. (2013). Déjà vu diplomacy: South Korea's Middle East policy under Lee Myung-bak. Contemporary Arab Affairs, 6 (4): 552-566. DOI: 10.1080/17550912.2013.850772.

Azad, S. (2018). In Quest of a Second Boom. South Korea's Middle East Policy under Park Geun-hye. Contemporary Arab Affairs, 11 (1-2): 257-278. DOI: 10.1525/ caa.2018.000015.

Chun, C., Lee, S. J. (ed.). (2016). East Asian Security and South Korea's Middle Power Diplomacy. In: Transforming Global Governance with Middle Power Diplomacy: South Korea's Role in the $21^{\text {st }}$ Century. New York: Palgrave Macmillan. 15-34. ISBN 978-1-137-59359-7.

Jeong, H. W. (2019). Beyond Resource Diplomacy and Economic Statecraft: UAE-ROK Relations in the $21^{\text {st }}$ Century. Asian Journal of Middle Eastern and Islamic Studies, 13 (2): 226 - 245. DOI: 10.1080/25765949.2019.1605569.

Lee, S. J. (2016). South Korea Aiming to Be an Innovative Middle Power. In: Transforming Global Governance with Middle Power Diplomacy: South Korea's Role in the $21^{\text {st }}$ Century. New York: Palgrave Macmillan. 1-13. ISBN 978-1-13759359-7.

Levkowitz, A. (2013). South Korea 's Middle East Polic. A. Ramat Gan: The Begin-Sadat Center for Strategic Studies. 38 p. ISSN 0793-1042.

Park, Y. E., Chaffar, S., Kim, M.-S., Ko, H. Y. (2017). Predicting Arab Consumers' Preferences on the Korean Contents Distribution. Journal of Distribution Science, 15 (4): 33 40. DOI: $10.15722 /$ jds.15.4.201704.33.

Song, N. (2015). (2015). Islam and South Korea's Middle East Diplomacy. BAKS Papers, 16 (3): $60-75$.

Song, N. (2013). The Strategic Partnership between South Korea and the United Arab Emirates. Güvenlik Stratejileri Dergisi (Security Strategies Journal), 17 (9): 23 - 48. 